\title{
ASSÉDIO E SOFRIMENTO MORAL DOS TRABALHADORES DE ENFERMAGEM: uma revisão integrativa da bibliografia
}

Ernandes Gonçalves DIAS*

\begin{abstract}
*Enfermeiro Mestrando do Programa de Tecnologia e Inovação em Enfermagem na USP-Ribeirão Preto. Especialista em Docência na Saúde e Enfermagem do Trabalho. Docente na Faculdade Presidente Antônio Carlos de Porteirinha e Faculdade Verde Norte.

Faculdade Presidente Antônio Carlos de Porteirinha - FUPAC - Porterinha - Minas Gerais

Faculdade Verde Norte - FAVENORTE - Mato Verde - Minas Gerais

nandesenf@usp.br
\end{abstract}

Recebido em: 04/07/2016 - Aprovado em: 11/01/2017 - Disponibilizado em: 01/07/2017

\begin{abstract}
RESUMO:
Trata-se de uma revisão da literatura brasileira realizada a partir de artigos originais publicados nos últimos cinco anos nas Bases de Dados da Biblioteca Virtual em Saúde, indexados pela Medline, SciELO e Lilacs, cujo objetivo foi verificar as evidências da prática do assédio e sofrimento moral com os trabalhadores de enfermagem. Os dados foram levantados em janeiro e fevereiro de 2016, utilizando descritores controlados, combinados com operadores booleanos e resultou em 07 artigos selecionados. Todos os trabalhos foram realizados na região Sul do Brasil e envolveram 1524 profissionais de enfermagem. As evidências científicas indicam que os fatores desencadeantes de assédio e sofrimento moral podem ser relacionados à assistência e relacionamento interpessoal e a fatores da gestão. Os fatores da assistência e relacionamento interpessoal são a falta de competência da equipe, questionamentos das decisões tomadas, críticas verbais ao trabalho e desrespeito a autonomia do paciente, enquanto os ligados a gestão são falta de diálogo entre chefia e comandados e falta de acesso a programas de educação permanente. Conclui-se que há necessidade de abertura de espaços para reflexões, diálogo e discussões dos problemas morais que envolvam os atores da de enfermagem e da gestão nas instituições.
\end{abstract}

Palavras-chave: Moral. Serviços de Enfermagem. Equipe de Enfermagem.

\section{HARASSMENT AND MORAL SUFFERING OF NURSING WORKERS: a integrative review of the literature}

\begin{abstract}
:
This is a review of the Brazilian literature made from original articles published in the last five years in the Virtual Library Database Health, indexed by Medline, SciELO and Lilacs, whose purpose was to verify the evidence of the practice of harassment and suffering moral with the nursing staff. The data were collected in January and February 2016, using controlled descriptors, combined with Boolean operators and resulted in 07 selected articles. All work was carried out in southern Brazil and involved 1524 nurses. Scientific evidence indicates that the triggering factors of harassment and moral suffering may be related to care and interpersonal factors and management. The factors of care and interpersonal relationships are the lack of competence of the team, questioning the decisions taken, verbal criticism of the work and disregard the autonomy of the patient, while those related to management are lack of dialogue between management and controlled and lack of access to programs continuing education. It is concluded that there is need to open spaces for reflection, dialogue and discussions of moral issues involving the actors of nursing and management institutions.
\end{abstract}

Keywords: Morale. Nursing Services. Nursing, Team. 


\section{INTRODUÇÃO}

A enfermagem atua com compromisso no cuidado do homem e expõe suas debilidades e fortalezas ao trabalhar com a diversidade de sujeitos, situações de cuidado, tecnologia e recursos humanos e materiais. Os embates da prática diária, as situações conflitantes e os dilemas acompanham o profissional, haja vista que são problemas da prática, técnicos, éticos, morais, sociais, econômicos e políticos (SCHNEIDER; RAMOS, 2012).

Os dilemas éticos e morais do trabalho da Enfermagem são situações embaraçosas, qualquer que seja o campo de atuação. $\mathrm{Na}$ verdade o dilema nos coloca diante da dificuldade de escolher a solução ideal em relação à situação, seja de assédio ou sofrimento (GERMANO, 2013).

O fenômeno do assédio e sofrimento moral, até pouco tempo, foi desconhecido e ignorado, mesmo sendo imposto aos escravos desde o tempo da colonização no Brasil. É um fenômeno tão antigo quanto o próprio trabalho (AZEVEDO, 2011).

Os trabalhadores de enfermagem vivenciam frequentemente problemas $\mathrm{e}$ conflitos morais que podem levar ao sofrimento moral. O sofrimento moral é doloroso, porém pode ser um mobilizador para o questionamento, o diálogo e o enfrentamento coletivo, na instituição, das tensões presentes nas ações profissionais, que repercutem no cuidado dos doentes. Vivenciar o sofrimento moral de modo solitário intensifica o peso negativo deste sentimento e contribui para a sensação de impotência, desamparo e culpa com o abandono da profissão (LUNARDI et al., 2009).

Vivemos um momento marcado por profundas mudanças nos campos da política, educação e saúde, que exigem respostas do trabalho em saúde e da educação para o trabalho (SCHAEFER; JUNGES, 2014). Assim, na formação inicial e permanente de profissionais de saúde é necessária a compreensão crítica das experiências vividas. O ensino da ética precisa possibilitar a reflexão sobre os valores, a cultura e a tomada de decisões em um contexto real para favorecer o desenvolvimento de meios de enfrentamento dos desafios morais da profissão (BURGATTI; BRACIALLI; OLIVEIRA, 2013).

Medidas eficazes de enfrentamento do assédio e sofrimento moral no ambiente de trabalho são importantes, porém, não são suficientes se não houver uma política na organização que impeça esse tipo de violência (FONTES et al., 2013).

É recomendado que as instituições implantem ações de melhoria das condições de trabalho e da comunicação nos ambientes, onde a enfermagem atua, para assim favorecer o enfrentamento, tomada de decisão, exercício 
da autonomia, e, principalmente, a qualidade do cuidado de enfermagem e a satisfação de seus trabalhadores (DALMOLIN et al., 2014a).

Porém, é visível a inércia dos gestores e empregadores no que se refere às questões que envolvem medidas de controle e prevenção da violência nas instituições de saúde. Do ponto de vista dos trabalhadores, poucas medidas de prevenção e controle do assédio e sofrimento existem nas instituições. É frequente não se identificar medidas simples de prevenção como adoção de registro interno das ocorrências anteriores praticadas por funcionários e clientes, além de treinamentos sobre como lidar, enfrentar e controlar essas situações no ambiente de trabalho (LIMA; SOUSA, 2015).

Dessa maneira, a demanda ética na prática e o consequente sofrimento moral são realidades presentes no trabalho da enfermagem nos diferentes serviços de saúde. Para lidar com essas questões, os profissionais usam recursos de enfrentamento que podem ser positivos, quando levam ao diálogo e à reflexão, e podem ser negativos, quando fazem o profissional aceitar e se conformar com a realidade, predispondo-se ao sentimento de sofrimento moral. Os profissionais eticamente competentes possuem maior habilidade para enfrentar as questões éticas da prática e, por isso, conseguem lidar melhor com o assédio e o sofrimento moral, assim como suas consequências (SCHAEFER; VIEIRA, 2015).

Enfocar o assédio e sofrimento moral provocado por problemas e dilemas morais presentes no trabalho da enfermagem, assistência, ensino e pesquisa, é fundamental não apenas para desvelar o fenômeno, mas também, para destacar a necessidade de problematização e valorização da dimensão ética do trabalho em saúde (LUNARDI et al., 2009).

Frente às considerações apresentadas, o estudo pretendeu responder ao problema: qual a evidências entre assédio e sofrimento moral e a profissão de enfermagem? Dessa maneira, teve como objetivo verificar as evidências da prática do assédio e sofrimento moral com os trabalhadores de enfermagem de acordo a literatura nacional dos últimos cinco anos.

\section{METODOLOGIA}

Trata-se de uma revisão integrativa da bibliografia do tipo descritiva e qualitativa, realizada a partir de consulta a 07 artigos científicos originais, publicados em periódicos nacionais em Língua Portuguesa entre os anos 2011 e 2015, indexados nas Bases de Dados da Biblioteca Virtual em Saúde/BIREME (BVS) Medical Literature Analysis and Retrieval System Online (Medline), Literatura Latino-Americana e do 
Caribe em Ciências da Saúde (Lilacs) e Scientific Electronic Library Online (SciELO).

A revisão sistemática da literatura é um tipo de investigação focada em questão bem definida e visa identificar, selecionar, avaliar e sintetizar as evidências relevantes sobre determinada área do conhecimento (GALVÃO; PEREIRA, 20014).

Os dados foram levantados nos meses de janeiro e fevereiro de 2016, utilizando os descritores controlados e não controlados combinados com operadores booleanos: "sofrimento moral" AND "enfermagem", "assédio moral" AND "enfermagem" e "ética” AND “enfermagem". Quando os artigos que apresentaram duplicidade nas Bases de Dados, optou-se por considerar o primeiro trabalho identificado.

Por conveniência do estudo, as publicações de teses, dissertações ou monografias não foram consideradas devido à limitação do acesso ao material e considerados artigos que continham o Sofrimento moral e o Assédio moral à profissionais de saúde como assunto central.

Os trabalhos selecionados foram identificados, lidos na íntegra e avaliados para sintetizar as evidências que a literatura apresenta sobre o assédio e o sofrimento moral entre trabalhadores de enfermagem. Os níveis de evidências foram identificados de acordo as recomendações de Melnyk e
Fineout-Overholt (2011), que consideram o delineamento do estudo para classificar o nível de evidência.

\section{DESENVOLVIMENTO}

O Quadro 1 mostra as características dos trabalhos avaliados conforme identificados ao usar a metodologia proposta. Os artigos tiveram em média cinco autores e foram publicados pela revista da Escola de Enfermagem da Universidade São Paulo ou pela revista Latino-Americana de Enfermagem. As pesquisas foram do tipo survey, descritivas, exploratórias e transversais com abordagem quantitativa em seis delas.

Apesar de está embutido no objetivo realizar o levantamento referente aos últimos cinco anos, não foi encontrado nenhum artigo que atendesse aos critérios desta pesquisa nos anos de 2011 e 2015. Todos os trabalhos foram realizados na região Sul do Brasil e envolveram 1524 profissionais de enfermagem (Enfermeiros, Técnicos e Auxiliares), trabalhadores em diversas áreas de atuação, porém sobressaíram os estudos realizados em hospitais.

\section{Evidências entre assédio e sofrimento moral dos trabalhadores de enfermagem}


Quadro 1 - Características dos estudos publicados sobre o assunto assédio e sofrimento moral entre trabalhadores de enfermagem, disponíveis na literatura brasileira entre 2011 e 2015 * $^{*}$

\begin{tabular}{|c|c|c|c|c|c|c|c|c|c|}
\hline Título & Autor (es) & Revista & $\begin{array}{l}\text { Tipo de } \\
\text { Estudo }\end{array}$ & Abordagem & Local & Ano & Sujeitos & $\begin{array}{c}\text { Nível de } \\
\text { Evidência }\end{array}$ & DOI \\
\hline $\begin{array}{l}\text { Vivência do sofrimento } \\
\text { moral na } \\
\text { enfermagem: percepção } \\
\text { da enfermeira }\end{array}$ & $\begin{array}{l}\text { Barlem } \\
\text { Lunardi, } \\
\text { Lunardi, } \\
\text { Dalmolin, } \\
\text { Tomaschewski, } \\
\text { JG. }\end{array}$ & $\begin{array}{l}\text { Rev Esc } \\
\text { Enferm USP }\end{array}$ & Survey & Quantitativo & $\begin{array}{l}\text { Hospital } \\
\text { Filantrópico no } \\
\text { Sul do Brasil }\end{array}$ & 2012 & 124 enfermeiras & IV & $\begin{array}{l}\underline{\text { http://dx.doi.org/10.1 }} \\
\underline{\text { 590/S0080- }} \\
\underline{62342012000300021}\end{array}$ \\
\hline $\begin{array}{l}\text { Variáveis envolvidas na } \\
\text { percepção do assédio } \\
\text { moral no ambiente } \\
\text { laboral da Enfermagem }\end{array}$ & $\begin{array}{l}\text { Fontes KB., } \\
\text { Carvalho, MDB. }\end{array}$ & $\begin{array}{l}\text { Rev. Latino- } \\
\text { Am. } \\
\text { Enfermagem }\end{array}$ & $\begin{array}{l}\text { Descritivo, } \\
\text { exploratório }\end{array}$ & Quantitativo & $\begin{array}{l}\text { Maringá, } \\
\text { Paraná }\end{array}$ & 2012 & 230 enfermeiros & III & $\begin{array}{l}\underline{\text { http://dx.doi.org/10.1 }} \\
\underline{590 / \mathrm{S} 0104-} \\
\underline{11692012000400017}\end{array}$ \\
\hline $\begin{array}{lr}\text { Sofrimento moral em } \\
\text { trabalhadores } & \text { de } \\
\text { enfermagem } & \end{array}$ & $\begin{array}{l}\text { Barlem ELD., } \\
\text { Lunardi VL., } \\
\text { Lunardi, GL., } \\
\text { Tomaschewski- } \\
\text { Barlem JG., } \\
\text { Silveira, RS., } \\
\text { Dalmolin GL. }\end{array}$ & $\begin{array}{l}\text { Rev. Latino- } \\
\text { Am. } \\
\text { Enfermagem }\end{array}$ & $\begin{array}{l}\text { Survey, } \\
\text { exploratório, } \\
\text { descritivo, } \\
\text { transversal }\end{array}$ & Quantitativo & $\begin{array}{l}\text { Dois hospitais } \\
\text { do Rio Grande } \\
\text { do Sul }\end{array}$ & 2013 & $\begin{array}{l}247 \text { trabalhadores de } \\
\text { enfermagem } \\
\text { (Enfermeiros, Técnicos e } \\
\text { Auxiliares) }\end{array}$ & III & $\begin{array}{l}\underline{\text { http://dx.doi.org/10.1 }} \\
\text { 590/S0104-} \\
\underline{11692013000700011}\end{array}$ \\
\hline $\begin{array}{lll}\text { Fatores } & \text { associados } & \text { ao } \\
\text { assédio } & \text { moral } & \text { no } \\
\text { ambiente } & \text { laboral } & \text { do } \\
\text { enfermeiro } & & \\
& & \end{array}$ & $\begin{array}{l}\text { Fontes KB., } \\
\text { Santana RG., } \\
\text { Pelloso SM., } \\
\text { Carvalho MDB. }\end{array}$ & $\begin{array}{l}\text { Rev. Latino- } \\
\text { Am. } \\
\text { Enfermagem }\end{array}$ & $\begin{array}{l}\text { Descritivo, } \\
\text { exploratório }\end{array}$ & Quantitativo & $\begin{array}{l}\text { Maringá, } \\
\text { Paraná }\end{array}$ & 2013 & 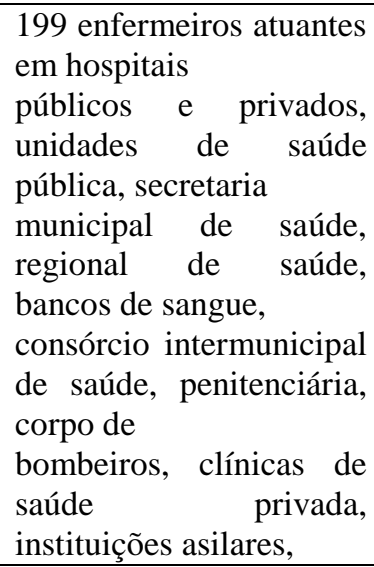 & III & $\begin{array}{l}\text { http://dx.doi.org/10.1 } \\
\text { 590/S0104- } \\
\underline{11692013000300015}\end{array}$ \\
\hline
\end{tabular}




\begin{tabular}{|c|c|c|c|c|c|c|c|c|c|}
\hline & & & & & & & $\begin{array}{llc}\text { planos de } & \text { saúde } & \text { e } \\
\text { Serviços de urgência } & \text { e } \\
\text { emergência } & & \end{array}$ & & \\
\hline $\begin{array}{lr}\text { Sofrimento moral } & \text { no } \\
\text { cotidiano } & \text { da } \\
\text { enfermagem: } & \text { traços } \\
\text { ocultos de } & \\
\text { poder e resistência } & \end{array}$ & $\begin{array}{l}\text { Barlem ELD., } \\
\text { Lunardi VL., } \\
\text { Lunardi GL., } \\
\text { Tomaschewski- } \\
\text { Barlem JG., } \\
\text { Silveira RS. }\end{array}$ & $\begin{array}{l}\text { Rev. Latino- } \\
\text { Am. } \\
\text { Enfermagem }\end{array}$ & $* *$ & Qualitativo & $\begin{array}{l}\text { Um hospital } \\
\text { universitário } \\
\text { do extremo Sul } \\
\text { do Brasil }\end{array}$ & 2013 & $\begin{array}{lr}15 \text { trabalhadores } & \text { de } \\
\text { enfermagem } & (05 \\
\text { enfermeiros, 06 técnicos } \\
\text { de enfermagem e } & 04 \\
\text { auxiliares } & \text { de } \\
\text { enfermagem) } & \\
\end{array}$ & IV & $\begin{array}{l}\underline{\text { http://dx.doi.org/10.1 }} \\
\underline{\text { 590/S0104- }} \\
\underline{11692013000100002}\end{array}$ \\
\hline $\begin{array}{l}\text { Enfermeiros, técnicos e } \\
\text { auxiliares de } \\
\text { enfermagem: quem } \\
\text { vivencia maior } \\
\text { sofrimento moral? }\end{array}$ & $\begin{array}{lr}\text { Dalmolin } & \text { GL., } \\
\text { Lunardi } & \text { VL., } \\
\text { Lunardi } & \text { GL., } \\
\text { Barlem } & \text { ELD., } \\
\text { Silveira RS. } & \\
\end{array}$ & $\begin{array}{l}\text { Rev Esc } \\
\text { Enferm USP }\end{array}$ & $\begin{array}{l}\text { Survey } \\
\text { Exploratório } \\
\text { descritivo }\end{array}$ & Quantitativo & $\begin{array}{l}\text { Três hospitais } \\
\text { no Sul } \\
\text { do Rio Grande } \\
\text { do Sul }\end{array}$ & 2014 & $\begin{array}{l}334 \text { trabalhadores de } \\
\text { enfermagem } \\
\text { (Enfermeiros, Técnicos e } \\
\text { Auxiliares) }\end{array}$ & III & $\begin{array}{l}\frac{\text { http://dx.doi.org/10.1 }}{590 / \mathrm{S} 0080-} \\
\underline{62342014000030001} \\
\underline{9}\end{array}$ \\
\hline 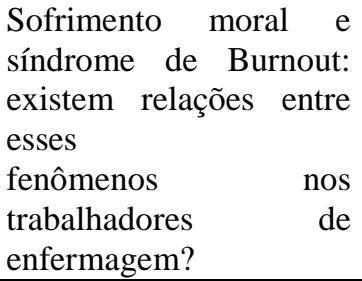 & $\begin{array}{l}\text { Dalmolin GL., } \\
\text { Lunardi VL., } \\
\text { Lunardi GL., } \\
\text { Barlem ELD., } \\
\text { Silveira RS. }\end{array}$ & $\begin{array}{l}\text { Rev. Latino- } \\
\text { Am. } \\
\text { Enfermagem }\end{array}$ & Survey & Quantitativo & $\begin{array}{l}\text { Três hospitais } \\
\text { no Sul } \\
\text { do Rio Grande } \\
\text { do Sul }\end{array}$ & 2014 & $\begin{array}{l}375 \text { trabalhadores de } \\
\text { enfermagem } \\
\text { (Enfermeiros, Técnicos e } \\
\text { Auxiliares) }\end{array}$ & III & $\begin{array}{l}\underline{\text { http://dx.doi.org/10.1 }} \\
\underline{590 / 0104-} \\
\underline{1169.3102 .2393}\end{array}$ \\
\hline
\end{tabular}

Fonte: Dados da pesquisa. 2016.

*Para os anos 2011 e 2015 não foram encontrados artigos nas Bases de Dados seguindo a metodologia deste estudo.

** Ignorado 
Em um estudo realizado com 124 enfermeiras em hospitais do sul do Brasil com o objetivo de conhecer a percepção do sofrimento moral vivenciado, relacionando frequência e intensidade destes, os profissionais de enfermagem apresentam maior percepção de vivência de sofrimento moral associada à falta de competência da equipe de trabalho e na negação do papel da enfermeira como advogada do paciente. Para os autores, a percepção da vivência de sofrimento moral, neste caso, reforça a necessidade de constantes indagações, reflexões e discussões pelas equipes de trabalho, abordando os problemas morais e o sofrimento moral enfrentados pelos trabalhadores. Dessa forma, os autores recomendam que seja realizado outros estudos sobre problemas morais, em especial, sofrimento moral na enfermagem e saúde, para contribuir com a transformação da realidade, mediante o enfrentamento de situações do ambiente de trabalho, reconhecidas como aceitáveis pelos profissionais, apesar de se caracterizarem como moralmente inadequadas (BARLEM et al., 2012).

Em um estudo realizado com 230 enfermeiros do serviço público e privado de Maringá no Paraná, em dois hospitais, 22 unidades de saúde e cinco outros serviços ambos públicos e 11 hospitais e 20 outros serviços ambos privados com o objetivo de identificar a percepção de enfermeiros sobre o assédio moral no trabalho, condutas vivenciadas e as variáveis envolvidas, os autores inferiram que o ambiente laboral e relacionamento interpessoal são fatores preponderantes na determinação da ocorrência do fenômeno, pois os fatores associados ao assédio moral foram predominantemente ocupacionais. As condutas de assédio moral mais referidas pelos sujeitos foram "questionamento de suas decisões" e "ataques verbais criticando trabalhos realizados" (FONTES; CARVALHO, 2012).

Os autores destacaram que a maior parte dos profissionais já presenciaram colegas sendo vítimas de condutas de assédio moral no trabalho e afirmam que esse tipo de violência é prática comum no ambiente organizacional da Enfermagem ou, mesmo, uma forma deficiente de gestão no trabalho, e recomendam que sejam criados espaços para discussão sobre a violência no trabalho, para que gestores possam estabelecer medidas estratégicas de prevenção e contenção desse tipo de violência, a fim de garantir a saúde, a dignidade e o bem-estar no trabalho (FONTES; CARVALHO, 2012).

No estudo realizado com 247 profissionais de enfermagem de dois hospitais do Rio Grande do Sul com o objetivo de analisar a frequência e a intensidade de 
sofrimento moral vivenciado por trabalhadores de enfermagem, os autores perceberam que compreender o sofrimento moral permite ir além do enfrentamento dos problemas morais dos próprios trabalhadores, chegando a configurar, de forma ampla e reflexiva, a situação da própria instituição e do sistema de saúde, que podem estar dificultando os cuidados de enfermagem e a atenção integral na saúde (BARLEM et al., 20123a).

Em um estudo realizado com 199 enfermeiros do serviço público e privado de Marigá-PR com o objetivo de identificar enfermeiros vítimas de assédio moral no trabalho e os fatores associados a essa prática. O estudo identificou que $11,56 \%$ dos enfermeiros foram vítimas de assédio moral e os fatores condicionantes foram ter filhos, atuar em unidades de saúde pública, trabalhar a pouco tempo na instituição (período inferior a 3 anos) e enfrentar a própria conduta de assédio moral no trabalho (FONTES et al., 2013).

Foi realizado também um estudo com 15 trabalhadores de enfermagem de um hospital universitário do extremo sul do Brasil com o objetivo de conhecer as estratégias de resistência adotadas por trabalhadores de enfermagem, diante de situações de sofrimento moral, dentro da perspectiva ética, os autores perceberam que alguns profissionais pareciam utilizar estratégias de enfrentamento éticas, de modo a assegurar e preservar valores profissionais, porém, muitas vezes, a opção de alguns profissionais pode recair no imobilismo e na ausência de construção de estratégias éticas de resistência. Nesse sentido, os autores afirmam que para o enfrentamento das situações que resultam em sofrimento moral, os trabalhadores de enfermagem necessitam ultrapassar dimensões de aparente conformismo que, por vezes, se encontram, possivelmente por ainda acreditarem que a resolução da maior parte dos problemas do seu cotidiano de trabalho encontra-se na própria profissão e não em suas relações (BARLEM et al., 2013b).

$$
\text { No estudo realizado com } 334
$$
profissionais de enfermagem de três hospitais do sul do Rio Grande do Sul com o objetivo de identificar a frequência e intensidade de sofrimento moral vivenciadas por enfermeiros, técnicos e auxiliares de enfermagem. Foi identificados como fonte de sofrimento moral, a falta de competência na equipe de trabalho, o desrespeito à autonomia do paciente, as condições de trabalho insuficientes e o apego à terapêutica. Decorrente de análise das médias das questões que compuseram o constructo, o sofrimento moral parece relacionar-se a dificuldades dos trabalhadores de enfermagem em exercer poder e resistência em seus ambientes de 
atuação, contribuindo para a sua mortificação e negação de si frente à aparente aceitação das condições, mesmo que inadequadas. De acordo os autores, entre as categorias profissionais da enfermagem, os enfermeiros são os que apresentaram maior sofrimento moral, seguidos pelos auxiliares de enfermagem e os técnicos de enfermagem. Ressaltam ainda que o sofrimento moral parece manifestar-se mais em situações e ambientes em que não são realizadas reuniões na equipe de trabalho, e que há poucas possibilidades de diálogo com chefias e instituição; e em locais em que não ocorrem ações de educação permanente. Desse modo, os autores associam a vivência de sofrimento moral, principalmente, à organização do ambiente de trabalho, pois não se privilegia espaços de discussão, problematização, reflexão e valorização de situações vivenciadas no cotidiano do trabalho (DALMOLIN et al., 2014a).

Em um estudo realizado com 375 trabalhadores de enfermagem, atuantes em três distintos hospitais também do sul do Rio Grande do Sul com o objetivo e identificar relações entre sofrimento moral e síndrome de Burnout nas percepções das vivências de trabalhadores de enfermagem, os autores perceberam que existe uma baixa correlação entre o sofrimento moral e a síndrome de Burnout. Não foi possível estabelecer relações de causa e efeito entre esses dois fenômenos, visto que os modelos apresentados não foram significativos e apresentaram graus de explicação muito baixos. Os autores encontraram uma relação negativa e significativa entre a realização profissional e o sofrimento moral, ou seja, com o aumento da realização profissional ocorre diminuição da percepção de sofrimento moral. Esses achados, remetem à necessidade de os trabalhadores de enfermagem realizarem enfrentamentos em seus locais de atuação, para fortalecer seus conhecimentos, valores e crenças, bem como sua percepção do que é o melhor cuidado para os seus pacientes (DALMOLIN et al., 2014b).

\section{CONCLUSÃO}

Considerando que foram avaliados artigos indexados nas três principais e relevantes Bases de Dados, o quantitativo de trabalhos publicados revela que o tema em questão vem sendo pouco discutido nos últimos cinco anos. Todos os trabalhos publicados envolveram a região Sul do país e uma pequena quantidade de autores se interessaram pelo tema, uma vez que se repetem nos artigos publicados. Dessa forma, reforça-se a necessidade de que novas pesquisas nesse campo do conhecimento sejam incentivadas e que mais autores pelo 
País a fora trabalhem com a temática, a fim de que seja possível estabelecer evidências mais claras e significativas para o cenário nacional.

Quanto às evidências científicas para assédio e sofrimentos moral nos trabalhadores de enfermagem verificou-se que os fatores desencadeantes podem ser relacionados à assistência e relacionamento interpessoal e à fatores da gestão. Quanto aos fatores da assistência e relacionamento interpessoal o assédio e o sofrimento moral esteve relacionado a falta de competência da equipe, questionamentos das decisões tomadas, críticas verbais ao trabalho, desrespeito a autonomia do paciente e apego a prática terapêutica. Os fatores ligados à gestão são falta de diálogo entre chefia e comandados, falta de acesso a programas de educação permanente e dificuldades em exercer poder e resistência no ambiente de trabalho. Dessa forma a literatura deixa clara duas grandes vertentes para ocorrência do sofrimento moral que são o ambiente de trabalho associado ao relacionamento interpessoal.

Verificou-se que o sofrimento moral atinge toda categoria de enfermagem, porém os enfermeiros são os que mais convivem com essa realidade. No enfrentamento dessas condições muitos lidam de forma ética, enquanto muitos se imobilizam e não conseguem criar uma estratégia de enfretamento.
Conclui-se que há necessidade de abertura de espaços para reflexões, diálogo e discussões dos problemas morais que envolvam os atores da profissão de enfermagem e da gestão nas instituições. Estes espaços podem se tornar lócus de transformação das práticas de gestão inovadoras, assim como cenário de indutor de mudanças no sistema de saúde.

\section{REFERÊNCIAS}

\author{
AZEVEDO, A. L. O Assédio Moral no \\ Trabalho de Enfermagem: um risco \\ invisível, porém existente. 2011. 15f. \\ Monografia (Especialização) apresenta ao \\ curso de Pós-graduação Lato Sensu em \\ Enfermagem do Trabalho da Sociedade \\ Universitária Redentor. Leopoldina, fev. 2011. \\ BURGATTI, J, C.; BRACIALLI, L. A. D.; \\ OLIVEIRA, M. A. C. Ethical problems \\ experienced in a supervised curricular \\ internship in nursing in an integrated \\ curriculum. Rev Esc Enferm USP, 2013; \\ 47(4): 937-42. [acesso 21 jan. 2016]. \\ Disponível em: \\ http://dx.doi.org/10.1590/S0080- \\ 623420130000400023.
}

BARLEM, E. L. D. et al. Sofrimento moral em trabalhadores de enfermagem. Rev. Latino-

Am. Enfermagem; 2013a; 21(Spec): [09 telas], jan.fev. [acesso 15 jan. 2016].

Disponível em: http://dx.doi.org/10.1590/S010411692013000700011.

BARLEM, E. L. D. et al. Sofrimento moral no cotidiano da enfermagem: traços ocultos de poder e resistência. Rev. Latino-Am.

Enfermagem; 2013b; 21(1):[08 telas], 
jan./fev. [acesso 23 fev. 2016]. Disponível em: http://dx.doi.org/10.1590/S010411692013000100002.

BARLEM, E. L. D.; et al. Vivência do sofrimento moral na enfermagem: percepção da enfermeira. Rev Esc Enferm USP, 2012; 46(3):681-8. [acesso 08 jan. 2016]. Disponível em: http://dx.doi.org/10.1590/S008062342012000300021.

DALMOLIN, G. L. et al. Enfermeiros, técnicos e auxiliares de enfermagem: quem vivencia maior sofrimento moral? Rev Esc Enferm USP, 2014a; 48(3):521-9. [acesso 26 jan. 2016]. Disponível em: http://dx.doi.org/10.1590/S0080$\underline{623420140000300019 .}$.

DALMOLIN, G. L. et al. Sofrimento moral e síndrome de Burnout: existem relações entre esses fenômenos nos trabalhadores de enfermagem? Rev. Latino-Am.

Enfermagem; 2014b; 22(1): [08 telas], jan./fev. [acesso 11 fev. 2016]. Disponível em: http://dx.doi.org/10.1590/0104$\underline{1169.3102 .2393 .}$.

FONTES, K. B. et al. Fatores associados ao assédio moral no ambiente laboral do enfermeiro. Rev. Latino-Am. Enfermagem; 2013; 21(3): [07 telas], mai./jun. [acesso 01 fev. 2016]. Disponível em: http://dx.doi.org/10.1590/S0104$\underline{11692013000300015 .}$.

FONTES, K. B.; CARVALHO, M. D. B. Variáveis envolvidas na percepção do assédio moral no ambiente laboral da Enfermagem.

Rev. Latino-Am. Enfermagem; 2012; 20(4): [08 telas], jul./ago. [acesso 22 jan. 2016].

Disponível em: http://dx.doi.org/10.1590/S010411692012000400017.

GALVÃO, T. F.; PEREIRA, M. G. Revisões sistemáticas da literatura: passos para sua elaboração. Epidemiol. Serv. Saúde, Brasília,
2014; (1):183-184, jan./mar. [acesso 04 jan. 2016]. Disponível em: http://dx.doi.org/10.5123/S167949742014000100018.

GERMANO, R. M. A pesquisa e os dilemas éticos do trabalho da Enfermagem. Rev Bras Enferm. 2013; 66(esp): 76-9. [acesso 19 fev. 2016]. Disponível em: http://dx.doi.org/10.1590/S0034$\underline{71672013000700010 .}$.

LIMA, G. H. A.; SOUSA, S. M. A. Psychological violence in the Nursing work. Rev. Bras. Enferm. 2015; 68(5): 535-41. [acesso 18 jan. 2016]. Disponível em: http://dx.doi.org/10.1590/0034$\underline{7167.2015680508 \mathrm{i} .}$

LUNARDI, V. L. et al. Sofrimento moral e a dimensão ética no trabalho da Enfermagem. Rev Bras Enferm, Brasília; 2009; 62(4): 599603, jul./ago. [acesso 04 jan. 2016]. Disponível em: http://dx.doi.org/10.1590/S003471672009000400018 .

MELNYK, B. M.; FINEOUT-OVERHOLT, E. (2011). Evidence-based practice in nursing and healthcare: A guide to best practice. Philadelphia: Lippincott, Williams \& Wilkins.

SCHAEFER, R.; JUNGES, J. R. The Construction of Ethical Competence in the Perception of Primary Care Nurses. Rev. esc. enferm. USP, 2014; 48(2): 329-34, Apr. [acesso 02 fev. 2016]. Disponível em: http://dx.doi.org/10.1590/S0080$\underline{6234201400002000019 .}$.

SCHAEFER, R.; VIEIRA, M. Ethical Competence as a Coping Resource for Moral Distress in Nursing. Texto contexto - enferm. [online]. 2015, 24(2): 563-573. [acesso $07 \mathrm{fev}$. 2016]. Disponível em: http://dx.doi.org/10.1590/010407072015001032014. 
SCHNEIDER, D. G.; RAMOS, F. R. S.

Processos éticos de enfermagem no Estado de

Santa Catarina: caracterização de elementos

fáticos. Rev. Latino-Am. Enfermagem, 2012;

20(4): [09 telas], jul./ago. 